\title{
Correction to: Lipid class composition of annually bleached Caribbean corals
}

\author{
Sarah L. Solomon ${ }^{1} \cdot$ Andréa G. Grottoli $^{1}\left[\right.$ Mark E. Warner $^{2} \cdot$ Stephen Levas ${ }^{1,3} \cdot$ Verena Schoepf $^{1,4}$. \\ Agustí Muñoz-Garcia 5
}

Published online: 6 February 2020

○) Springer-Verlag GmbH Germany, part of Springer Nature 2020

\section{Correction to: Marine Biology \\ https://doi.org/10.1007/s00227-019-3616-z}

The author would like to correct the error in the Funding section of the original publication of the article. The corrected Funding section is given below:

Funding This study was funded by the National Science Foundation (OCE\#0825490 to A.G.G., OCE\#0825413 to M.E.W) and the Herbert W. Hoover Foundation (to A.G.G.).
Publisher's Note Springer Nature remains neutral with regard to jurisdictional claims in published maps and institutional affiliations.

The original article can be found online at https://doi.org/10.1007/ s00227-019-3616-z.

Andréa G. Grottoli

grottoli.1@osu.edu

1 School of Earth Sciences, The Ohio State University, Columbus, OH, USA

2 School of Marine Science and Policy, University of Delaware, Lewes, DE, USA

3 Department of Geography, Geology, and Environmental Science, University of Wisconsin-Whitewater, Whitewater, WI, USA

4 Oceans Graduate School, UWA Oceans Institute and ARC Centre of Excellence for Coral Reef Studies, The University of Western Australia, Crawley, WA, Australia

5 Department of Evolution, Ecology and Organismal Biology, The Ohio State University at Mansfield, Mansfield, OH, USA 